\title{
Concepções alternativas sobre microrganismos: alerta para a necessidade de melhoria no processo ensino- aprendizagem de biologia
}

\section{RESUMO}

Noalixon Faustino de Oliveira noalisonoliveira@hotmail.com 0000-0003-1782-4447 Universidade Federal de Campina Grande, Cuité, Paraíba, Brasil

Thamara de Medeiros Azevedo thamarabio@outlook.com

Universidade Federal Universidade Federal de Campin

Luiz Sodré Neto luizsodre@ufcq.edu.br

Universidade Federal de Campina Grande, Cuité, Paraíba, Brasil
O presente trabalho apresenta e discute os resultados de uma pesquisa realizada em uma escola estadual localizada no Seridó paraibano. A pesquisa objetivou analisar os conhecimentos dos 327 alunos do 1으, 2ㅇ e 3 ㅇ ano do Ensino Médio sobre os microrganismos, como também verificar a forma com que esses alunos interpretam as atividades desses seres relacionadas ao seu cotidiano. Diante dos resultados é possível considerar que os professores precisam utilizar alternativas de ensino que permitam um melhor desenvolvimento cognitivo, procurando identificar os conhecimentos prévios para poder mediar as relações entre o que se conhece e as novas informações.

PALAVRAS-CHAVE: Ensino de biologia. Concepções alternativas. Microbiologia. 


\section{INTRODUÇÃO}

No ensino da Biologia ainda são muito comuns as aulas tradicionais nas quais o professor tem os objetivos voltados para o que se considera como transmissão do conteúdo e os alunos, por sua vez, permanecem preocupados com a recepção das informações, que parecem verdades absolutas. Em função dos diferentes ramos abrangidos pela Biologia, os professores geralmente buscam suprir as dificuldades existentes por meio de aulas expositivas, complementando com outras modalidades didáticas para que o ensino não estimule apenas a memorização.

Para uma melhor abordagem dos conteúdos da biologia é necessário prioritariamente um comprometimento por parte dos professores na tentativa de superar algumas dificuldades de aprendizagem por meio de alternativas didáticas que possam tornar as aulas mais agradáveis e interessantes.

Além disso, sugere-se que haja uma busca pelo conhecimento trazido pelos estudantes, oriundo da sua vida cotidiana, para que o professor consiga articular as ideias contextualizando as novas informações. Tais conhecimentos prévios podem servir como base para uma re-estruturação mental para que os novos conceitos sejam aplicados e entendidos. Quando estas ideias estão articuladas de maneira que haja uma concepção formada, embora não seja necessariamente correta, é possível identificar a presença de concepções alternativas.

As concepções alternativas são os conhecimentos prévios dos alunos em relação a algum tema e, a partir destes, são construídos conhecimentos errôneos que podem comprometer o entendimento, apesar de serem considerados de fundamental importância para a produção de estratégias que possam ajudar a transformar as concepções alternativas dos discentes (COUTO E BOSSOLAN, 2012). Identificar esses conhecimentos prévios dos estudantes pode auxiliar o professor no momento de planejar suas aulas voltadas para o conteúdo de interesse, contribuindo ainda para uma melhor mediação dos conceitos científicos em sala de aula (CASTRO e BEJARANO, 2013).

A formação de concepções alternativas acerca dos microrganismos, por exemplo, ocorre durante as experiências cotidianas dos estudantes e, por esse motivo, são influenciadas predominantemente pelo senso comum (FERNANDES e CAMPOS; MARCELINO JÚNIOR, 2010). Embora essas concepções trazidas pelos discentes para o ambiente escolar frequentemente se distanciem dos conhecimentos científicos, o professor deve toma-las como ponto de partida durante a abordagem da Microbiologia, pois segundo Mortimer (2000) até que a nova concepção não seja de fato plausível para os alunos, os possíveis conceitos equivocados adquiridos em vivência social não serão superados.

O estudo de ramos específicos da Biologia, caracteristicamente marcados pelo seu caráter microscópico como a Microbiologia, a Genética, a Citologia, dentre outras, fascina ao mesmo tempo em que gera certo receio dos estudantes pelo grande volume de conteúdos expostos e pela forma tradicional e descontextualizada de trabalho de alguns professores, o que possivelmente interfere na qualidade da aprendizagem. Dentre as áreas das Ciências Biológicas que exigem maior abstração, a Microbiologia é destacada pela falta de aulas que estimulem os alunos a terem uma visão positiva sobre esses seres microscópicos. Segundo Hitomi et al. (2013), a Microbiologia geralmente é apresentada nas 
escolas de forma teórica, com poucas aulas experimentais. A falta de materiais e equipamentos para a realização das aulas práticas é um dos principais problemas da não execução dessa metodologia de aula, o que torna, mais difícil o aprendizado significativo do ensino de biologia.

Algumas estratégias que podem ser usadas para o trabalho com os estudantes do ensino básico, principalmente quando se tratam das áreas de estudo supracitadas, servem como complementos das tradicionais aulas teóricas que ainda predominam em muitas escolas brasileiras. A interação entre a teoria e prática, para alguns autores, como Lima e Garcia (2011), Barbosa e Barbosa (2010) e Albuquerque, Braga e Gomes (2012), pode favorecer também a interação dos alunos durante o desenvolvimento de aulas como as experimentais.

Na concepção de Lima e Garcia (2011), aulas práticas são fundamentais para compreensão dos conteúdos e não limita o aluno a ter um formato pronto que o faça ter uma resposta esperada, mas que possam ajudar no desempenho de habilidades durante a construção do conhecimento científico. Essa metodologia permite fugir do modelo de aulas tradicionais, as quais não contribuem para a formação do conhecimento pelos alunos, pelo fato de atribuí-los a função de expectadores de conteúdos. Barbosa e Barbosa (2010), também afirmam que as aulas práticas são de suma importância para o desenvolvimento cognitivo dos alunos, podendo ajudar na interpretação e compreensão dos conteúdos microbiológicos.

Para Albuquerque, Braga e Gomes (2012) existe um grande mito quando se fala de aulas práticas, no sentido de que para realizar esse modelo de aula é necessário alto investimento com materiais como vidrarias, estufa, armário entre outros. Para esses autores, um objeto científico é simplesmente algum artefato que possa ajudar no processo de pesquisa e aprendizagem dos alunos. Desta forma, através de materiais alternativos de baixo custo, as aulas práticas fluem de forma simples e dinâmica, favorecendo o aluno e o professor.

Outro método alternativo ao tradicional são as aulas de campo, que também são uma importante estratégia para o ensino de Biologia assim como para o processo de aprendizagem dos alunos. Na interpretação de Viveira e Diniz (2009), as aulas de campo pode ser uma ótima ideia de metodologia de ensino, onde existem várias alternativas de aprendizagem para os discentes, porém esse modelo de aula deve ser bem pensado e em seguida bem elaborado, evitando-se que a aula não perca o seu foco e não seja confundida com um dia de lazer. É fundamental que as aulas de campo também tenham o objetivo de auxiliar na construção do conhecimento.

As atividades lúdicas vêm sendo uma estratégia de ensino, nas quais são usados jogos ou brincadeiras como ferramentas educativas que tem o objetivo principal de realizar as atividades de forma prazerosa e contribuir para o processo de ensino-aprendizagem. As atividades lúdicas em sala trazem estímulos para os alunos e provocam os mesmos, o que propicia a construção de conhecimentos e o desbloqueio no pensamento (CABRERA, 2007).

Diante do exposto, o presente trabalho buscou identificar a presença de concepções alternativas sobre Microbiologia, em estudantes das turmas de $1^{\circ}, 2^{\circ}$ e $3^{\circ}$ anos do Ensino Médio, bem como discutir possíveis causas da formação dessas econômica e na importância biotecnológica dos microrganismos. Desse modo, 
pode-se utilizar a Microbiologia aplicada para facilitar a percepção da presença desses seres no dia-dia e favorecer o processo de ensino-aprendizagem do tema.

\section{METODOLOGIA DA PESQUISA}

O trabalho foi desenvolvido em três etapas distintas descritas no quadro 1.

Quadro 1 - Etapas para o desenvolvimento da pesquisa.

\begin{tabular}{|c|c|c|}
\hline Etapas & $\begin{array}{l}\text { Descrição do } \\
\text { evento }\end{array}$ & Local \\
\hline 1a Etapa & Elaboração do questionário & $\begin{array}{l}\text { Laboratório de Ensino de Microbiologia } \\
\text { (LabEnMicro) }\end{array}$ \\
\hline 2a Etapa & Aplicação dos questionários & $\begin{array}{l}\text { Escola Estadual de Ensino Médio } \\
\text { Professor Lordão, Picuí - PB }\end{array}$ \\
\hline 3a Etapa & $\begin{array}{l}\text { Análise e classificação dos } \\
\text { dados obtidos }\end{array}$ & $\begin{array}{l}\text { Laboratório de Ensino de Microbiologia } \\
\text { (LabEnMicro) }\end{array}$ \\
\hline
\end{tabular}

A primeira etapa consistiu na elaboração de um questionário com sete questões de múltipla escolha, onde os alunos tiveram a oportunidade de marcar uma ou mais alternativas. O questionário proposto teve como intuito analisar a visão que os alunos do Ensino Médio têm sobre a Microbiologia, assim como observar até que ponto esses discentes interligam os microrganismos ao cotidiano, como sua importância no meio ambiente, na produção de fármacos e nos ciclos biogeoquímicos existentes na natureza.

Foi realizada na segunda etapa do estudo a aplicação do questionário em todas as turmas do 10 , 2ㅇ e 3 ano do nível médio de uma escola da rede pública de ensino do município de Picuí - PB, com os alunos que fazem parte do programa Ensino Médio Inovador (ProEMI). Dos 420 alunos das turmas alvo, 327 responderam o questionário aplicado, sendo 162 estudantes do $1^{\circ}$ ano, 102 no $2^{\circ}$ ano e 63 do $3^{\circ}$ ano. A escola que foi submetida a pesquisa possui um total de 10 turmas funcionando o Ensino Médio, sendo 5 do 1ㅇano, 3 do 2ㅇa ano e 2 turmas que estão terminando o referido nível de ensino. Os alunos matriculados no ProEMI, tem uma faixa etária entre 14 e 25 anos.

A análise da pesquisa foi desenvolvida no Laboratório de Ensino de Microbiologia (LabEnMicro), da Universidade Federal de Campina Grande, Campus Cuité, PB. Os questionários foram analisados individualmente, classificando os percentuais das respostas para cada questão. Nesta 3 a etapa, observou-se alguns aspectos microbiológicos das bactérias e vírus, em relação ao ambiente em que eles vivem como também se observou o que os alunos lembram sobre tema 
proposto em aulas de Ciências e Biologia. Considerando que os conteúdos acerca dos microrganismos são, ou deveriam ser vistos previamente no Ensino Fundamental e trabalhados de maneira mais ampla a partir do 20 ano do Ensino Médio, o mesmo questionário foi aplicado em todas as turmas de Ensino Médio da escola.

\section{RESULTADOS E DISCUSSÃO}

A realização da pesquisa por meio de questionários fez-se com a intenção de analisar como os alunos do Ensino Médio da escola alvo concluem o referido nível de ensino, em relação as suas interpretações sobre entendimento dos microrganismos. As perguntas constituintes do questionário abrangeram aspectos referentes as bactérias, vírus, dentre outros assuntos que os alunos do Ensino Médio já deveriam ter visto durante o Ensino Fundamental. Apesar de o mesmo questionário ter sido aplicado para as turmas de 1을 ano, 2ㅇ ano e 3 o ano do Ensino Médio, não houve variações significativas entre as respostas. Por esse motivo, optou-se por quantificar as respostas de maneira geral, sem distinguir os dados separadamente entre as séries.

A figura 1 mostra os percentuais de respostas da 1a questão "Microrganismos são seres:" os resultados coletados mostram que de 327 pessoas, apenas 43 alunos $(13,43 \%)$ (coluna A) marcaram as alternativas "Pluricelulares" e "Unicelulares", mostrando que não há um bom entendimento por parte de alguns alunos sobre estes seres. Apenas 2 alunos (0,61\% (coluna B)) assinalaram simultaneamente as alternativas "Parasitas e de vida livre". As demais pessoas (282), 86,23\% (coluna C), marcaram outras respostas.

Figura 1 - Respostas dos alunos sobre conhecimentos básicos da microbiologia.

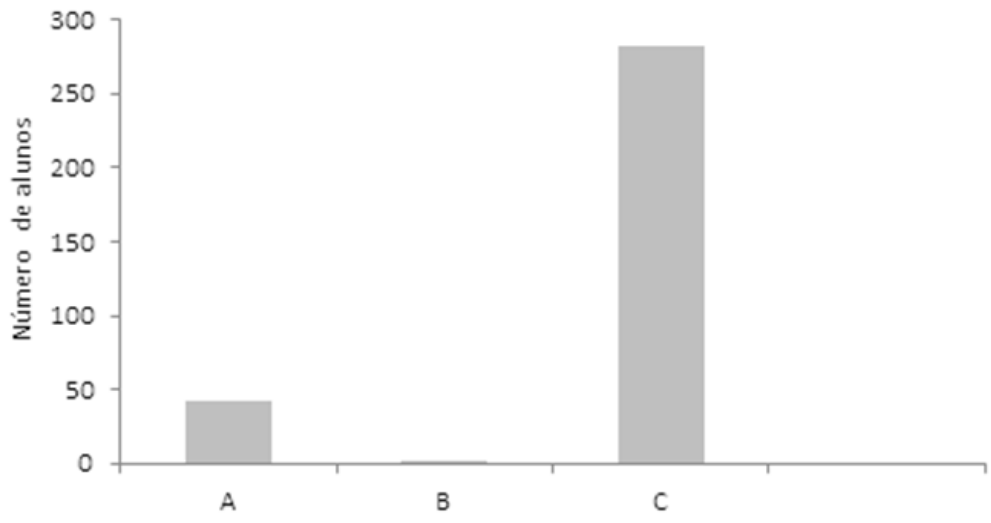


Albuquerque, Braga e Gomes (2012), enfatizam que há uma falta de inserção dos conteúdos microbiológicos no cotidiano dos alunos, o que provavelmente facilitaria a compreensão de forma mais ampla em que os alunos pudessem observar efeitos negativos da atividade microbiana, como a causa de doenças, como também associar os microrganismos aos inúmeros benefícios para a vida dos demais seres.

Quanto as bactérias, das respostas para a questão 2 "Em relação as bactérias, elas são:" 36,08\% (coluna A) marcaram a alternativa que afirmava que todas as bactérias são patogênicas (causadoras de doenças). Diante disso, pôde-se observar que uma parcela representativa de alunos tem uma visão distorcida sobre esses microrganismos. Em uma pesquisa realizada por Silva e Bastos (2012), foram obtidos resultados semelhantes, onde $34 \%$ dos discentes associaram as bactérias a seres causadores de doenças.

Alguns trabalhos recentemente publicados (LIMBERGER, SILVA e ROSITO, 2011; ANTUNES, PILEGGI e PAZDA, 2012; SILVEIRA, OLIVEROS e ARAÚJO, 2011) demonstram que os estudantes comumente apresentam concepções alternativas ao relatar que bactérias estão associadas fundamentalmente a doenças. Essas pesquisas relatam ainda que independentemente de os alunos já terem estudado ou não sobre o conteúdo, essa concepção continua sendo observada, evidenciando desta forma a dificuldade de alguns discentes em compreender sobre outras importâncias das bactérias.

Parte dos estudantes, referente ao percentual de 11,31\% (coluna B) afirmaram que as bactérias são algumas patogênicas, algumas importantes para a indústria e algumas são importantes para o ambiente, mostrando ter conhecimento sobre outras importâncias desses microrganismos, além da importância médica. Outros 52,61\% (coluna C) marcaram mais de uma alternativa, gerando incoerência no conjunto de respostas (Figura 2).

Figura 2 - Número de respostas referentes às importâncias das bactérias.

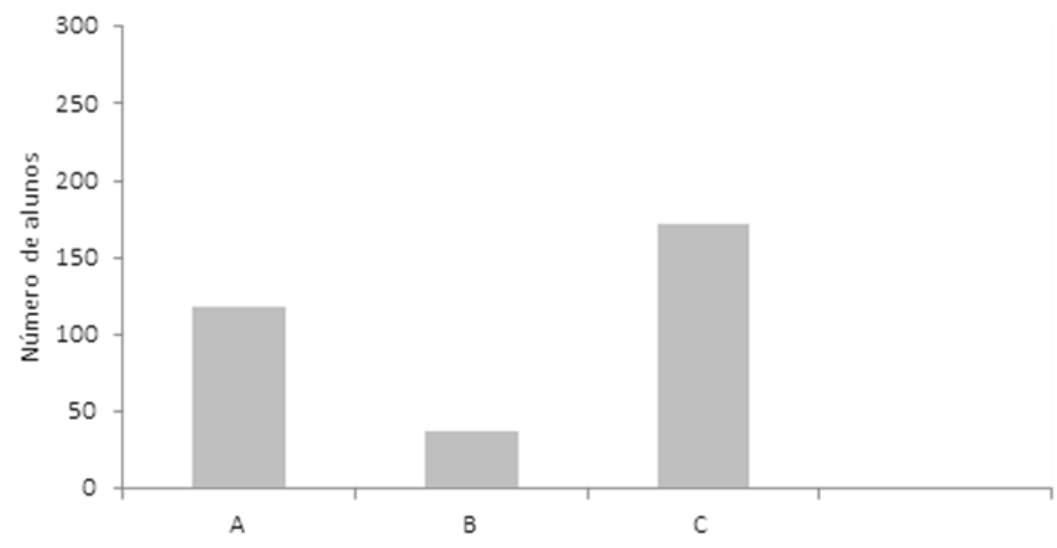

Tais resultados mostram que a visão de grande parte dos alunos do Ensino Médio ainda é reducionista, considerando estritamente as bactérias como causadoras de doenças. É com essa visão equivocada que os discentes têm, na maioria das vezes adquiridas por falta de abordagens adequadas por parte dos professores, que eles ficam impossibilitados de relacionar os microrganismos a outros aspectos do cotidiano, como a importância para a indústria e também para a manutenção do equilíbrio nos ecossistemas da Terra. 
Isso também é evidenciado pela pesquisa desenvolvida por Pessoa et al. (2012), na qual uma parte significativa dos alunos acredita que todas as bactérias são causadoras de doenças. Em um estudo sobre as bactérias com alunos do Ensino Médio, antes do desenvolvimento de um projeto sobre microrganismos, Brandão e Corazza (2008), afirmaram que os alunos tinham uma visão distorcida sobre esses seres microscópicos, percebendo as bactérias exclusivamente como seres prejudiciais à saúde.

Dentre algumas considerações sobre os vírus, a figura 3 corresponde aos resultados obtidos na terceira questão "quanto aos vírus, eles são:" 14,06 \% dos estudantes (Coluna A) marcaram a alternativa que afirmava que os vírus são seres vivos, 16,51\% (coluna B) afirmaram que não são seres vivos e $43,73 \%$ (coluna C) salientaram que os vírus são seres vivos apenas dentro de uma célula. 22,65 \% (coluna E) marcaram mais de uma alternativa e apenas 3,05\% (coluna D) assinalaram a alternativa que anulava todas as outras.

Figura 3 - Respostas das alternativas sobre características virais

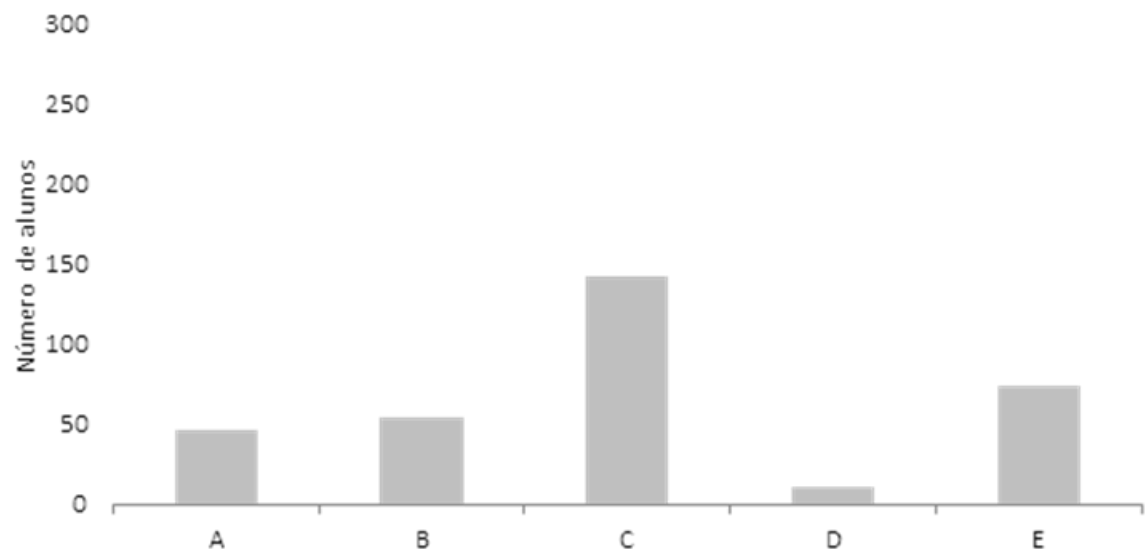

O número de respostas representado pela coluna $\mathrm{C}$ demonstra uma boa percepção dos discentes em relação aos vírus, que não são capazes de exercer suas atividades de maneira autônoma, sendo assim dependentes de uma célula hospedeira para expressarem as informações contidas no seu material genético e se multiplicarem.

Contrapondo esses resultados, Oliveros, Silveira e Araújo (2011) relataram em sua pesquisa que a maior parcela de alunos participantes afirmou que os vírus não são seres vivos. As considerações dos vírus como sendo seres vivos, não vivos, ou ora vivos, ora não vivos, parece permanecer entre os professores e estudantes do assunto. Embora sejam observadas essas variadas considerações nas pesquisas sobre esses microrganismos, sugere-se que eles sejam interpretados de duas maneiras, quando fora ou dentro de uma célula hospedeira, funcionando, portanto, como não vivos ou como vivos, respectivamente.

Das respostas para a questão 4 (Figura 4), na qual os alunos foram questionados sobre os locais onde possivelmente os microrganismos são encontrados: "Onde podem ser encontrados microrganismos patogênicas (causadores de doenças)?”, 66,36\% (coluna A) marcaram que são encontrados em todos os ambientes, sejam aquáticos, terrestres ou no ar, 4,58\% (coluna B) afirmaram que são encontrados em ambientes terrestres e aquáticos, 5,50\% 
(coluna C) marcaram que os microrganismos são encontrados apenas no ar, e $9,48 \%$ (coluna D) salientaram que são encontrados somente parasitando outros seres. $14,08 \%$ dos estudantes marcaram a alternativa denominada "outros", referentes à presença de microrganismos em outros locais que não fossem os indicados nas alternativas anteriores.

Figura 4 - Respostas dos alunos sobre os lugares onde são encontrados microrganismos patogênicos.

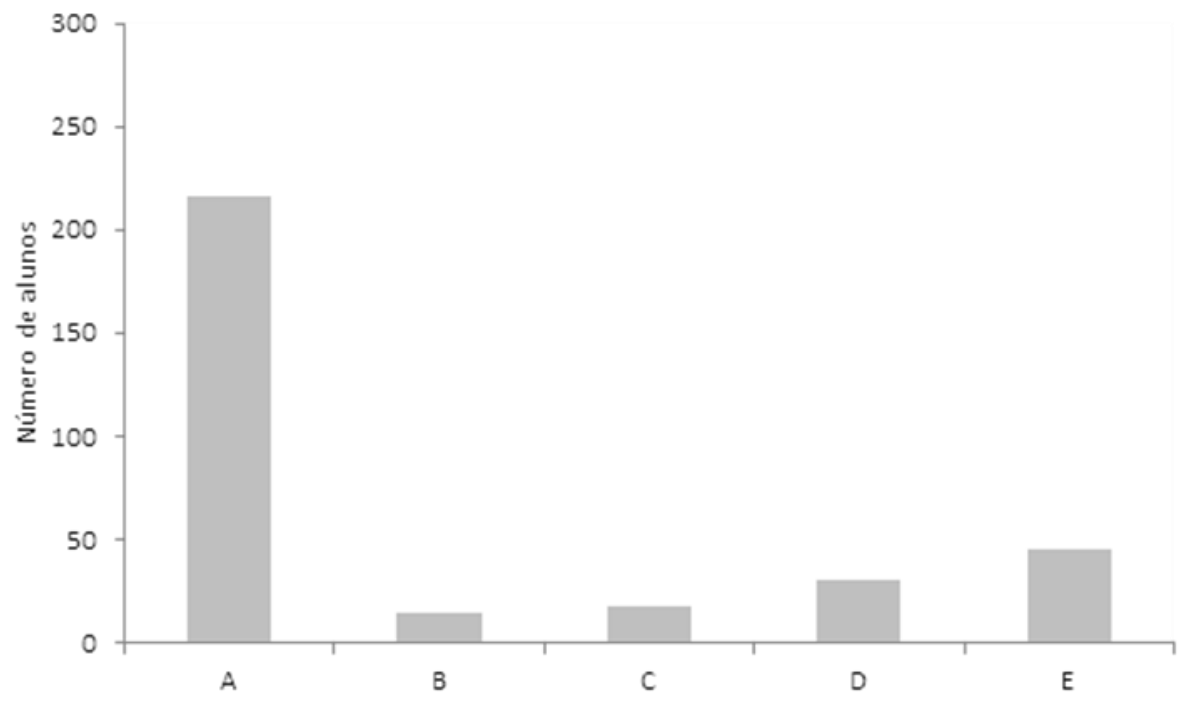

No trabalho de Silva e Bastos (2012), a maioria dos alunos também afirmou que os microrganismos estão presentes em todos os ambientes. Esse tipo de resposta aparece como uma das contradições quando é comparada com a questão na qual a maioria dos estudantes considera todos os microrganismos patogênicos.

A figura 5 mostra os resultados da 5a questão, "onde podem ser encontrados microrganismos não patogênicos (que não causam doenças)?" 29,35\% dos alunos (coluna A) marcaram que são encontrados em todos os ambientes, sejam aquáticos, terrestres ou no ar, 7,33\% (coluna B) afirmaram que são encontrados em ambientes terrestres, 18,65\% (coluna C) assinalaram que são encontrados em contato com outros seres vivos e $27,21 \%$ (coluna D) afirmaram que não existem microrganismos que não causam doenças. 
Figura 5 - Respostas dos alunos sobre os lugares onde são encontrados microrganismos não patogênicos.

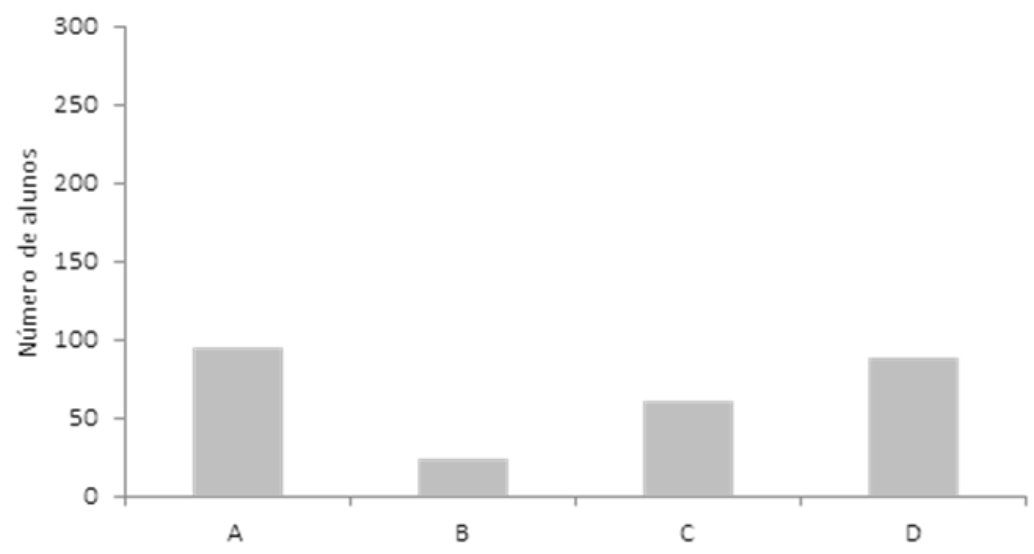

Grande parte dos alunos (29,35\%) entende que os microrganismos são encontrados em todos os ambientes, inclusive em lugares com altas variações de temperatura e umidade, como também participam de atividades vitais para os ciclos naturais. Por outro lado, um dado que chama muito a atenção é em relação a existência de microrganismos não patogênicos, para o qual 27,21\% demonstraram não conhecer sobre microrganismos que não causam doenças, afirmando que não existem seres com essa característica. Esses resultados corroboram os encontrados por Pessoa et al. (2012) que em sua pesquisa com 314 estudantes participantes, quase metade deles desconheciam microrganismos que não causam doenças.

Isso gera uma grande preocupação porque mostra uma visão equivocada dos estudantes do Ensino Médio sobre o assunto e reforça a necessidade de uma abordagem mais adequada por parte dos professores. Mesmo no estudo de um único assunto parece haver um distanciamento entre as ideias sobre os microrganismos, como se as suas populações fossem bem separadas, habitando lugares específicos, e como se as doenças fossem causadas exclusivamente por aqueles que têm apenas essa função.

O número de respostas para a 6a questão (Figura 6) "Na escola em que você estuda há aulas práticas para uma possível visualização de microrganismos?" foi de $54,74 \%$ para a resposta sim e de $45,26 \%$ para a resposta não. Esses dados também são preocupantes pelo fato de que quase a metade dos alunos não conhece sobre a existência de aulas práticas na própria escola. Este tipo de aula pode ajudar no entendimento de alguns conteúdos, principalmente quando envolve organismos que não podem ser visualizados sem auxílio de microscópio. 
Figura 6 - Respostas dos alunos sobre a realização de aulas práticas na escola.

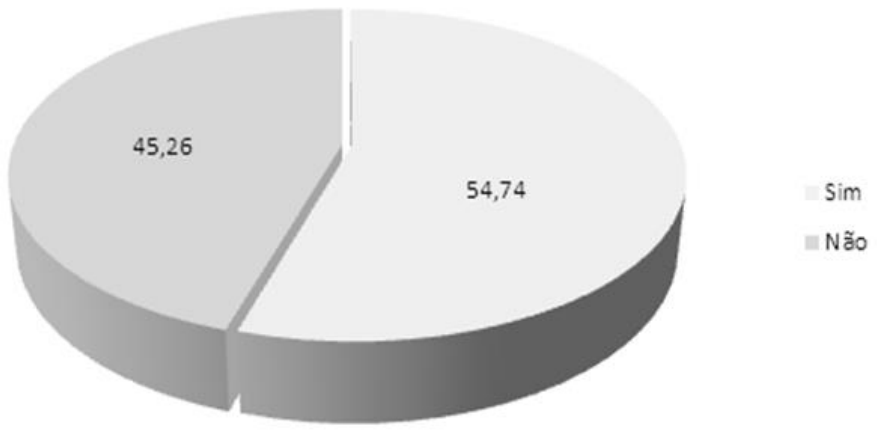

A maioria das respostas neste caso pode ser devido ao fato de a maioria das turmas do primeiro ano do ensino médio estar se familiarizando com a escola e não ter participado até o momento de aula com essa modalidade de ensino. Miranda, Leda e Peixoto (2013) afirmam que as atividades práticas favorecem uma dinamização dos conteúdos de Biologia, pois estimulam através do contato dos alunos com as práticas, a curiosidade, a atenção e em alguns casos a vocação científica. Numa pesquisa sobre aulas práticas no ensino de biologia, Lima e Garcia (2011) encontraram resultados sobre a consideração da importância desse método de ensino, tanto por alunos que tiveram, quanto por alunos que não tiveram essas aulas.

De modo geral, quando o assunto é microrganismo, como exposto na questão 7 , foi observado um baixo nível de entendimento da relação dos microrganismos com os aspectos abordados (Figura 7). Apenas 6 estudantes (1,83\%) (coluna C) consideraram que os microrganismos estão associados a indústria de alimentos e bebidas, enquanto a maioria, $141(43,11 \%)$ (coluna A), associaram exclusivamente a doenças, assim como na questão 2 , na qual a maior parte das respostas foi em relação a este tipo de associação. As demais respostas foram associações feitas a cadeias alimentares (coluna B) e fotossíntese coluna(D).

Figura 7 - Respostas sobre as associações que os alunos fazem aos microrganismos nas aulas de Ciências e Biologia.

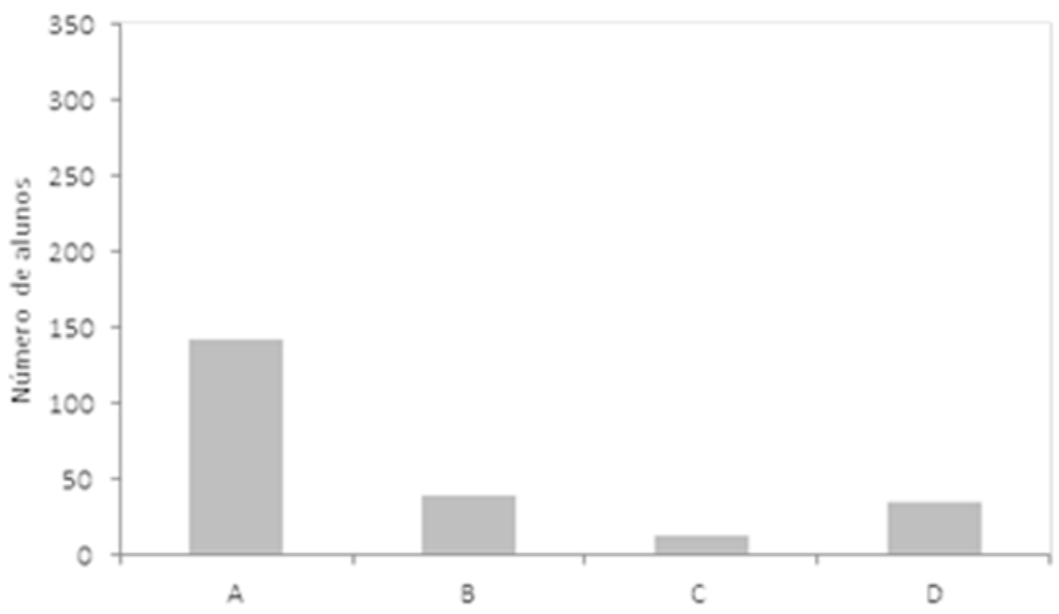


Apesar de os estudantes consumirem produtos da atividade microbiana, tanto na indústria alimentícia, quanto da indústria farmacêutica, a minoria consegue fazer essa relação. Outro ponto importante que é trabalhado de forma desconexa e contribui para a falta de uma compreensão mais abrangente do conteúdo é a presença dos microrganismos nas cadeias e teias alimentares, seja na produção primária, na produção secundária, na fixação de nitrogênio do ar, ou na decomposição da matéria orgânica.

Os microrganismos estão envolvidos em muitos aspectos relacionados à vida dos demais seres, inclusive do ser humano, desde o desenvolvimento de doenças até agindo favoravelmente aos nos inúmeros benefícios que eles podem nos oferecer de forma natural. Entretanto, por mais que existam muito mais microrganismos que causam o bem para sociedade, muitos alunos ainda associam esses seres, de forma errônea, estritamente às doenças (ALBUQUERQUE, BRAGA e GOMES, 2012).

\section{CONSIDERAÇÕES FINAIS}

Atualmente o processo de ensino-aprendizagem em Biologia vem passando por muitas dificuldades no sentido da formação dos alunos em relação a sociedade em que vivemos, que na maioria das vezes são influenciados por informações vinculadas pela mídia, causando grandes prejuízos ao saber científico. Desta forma, a preparação dos estudantes para discutir alguns temas relevantes no contexto atual, acaba ficando comprometida devido a existência de conhecimentos prévios equivocados.

Os resultados mostram que boa parte dos alunos do Ensino Médio tem uma visão distorcida sobre os microrganismos, em geral aliando-os apenas a agentes causadores de doenças, esquecendo que os mesmos são fundamentais para a manutenção da vida em nosso planeta.

Ao analisar os questionários aplicados para os alunos, ficou evidente que grande parte dos discentes não apresenta um bom entendimento sobre alguns aspectos da microbiologia, especialmente no que se refere às bactérias. Além disso, algumas ideias sobre os vírus também são equivocadas. Apesar de existir coerência no entendimento em alguns casos, ficou evidenciada a formação de concepções alternativas ao longo da formação básica dos estudantes, o que pode interferir no processo de ensino-aprendizagem do tema trabalhado, já que muitos dos professores não buscam alternativas para evitar a perpetuação dessas ideias.

Diante dos resultados apresentados, observou-se que os alunos sentem muitas dificuldades no entendimento sobre os microrganismos. $O$ uso de metodologias alternativas de ensino, buscando fugir das aulas tradicionais, poderia ser um dos fatores que contribuiriam para que as concepções alternativas, construídas pelos estudantes também em seu convívio social, fossem desmontadas e reformuladas para o favorecimento de uma aprendizagem mais coerente com os conhecimentos científicos.

Considerando que o tema abordado já tenha sido trabalhado no Ensino Fundamental, e disseminado pela mídia em alguns de seus aspectos, os professores podem usar esses conhecimentos prévios no Ensino Médio como ponto de partida para uma contextualização com o cotidiano dos discentes e 
promover um consequente entendimento adequado dos conceitos inerentes à Microbiologia na Educação Básica. 


\title{
Conceptions alternatives about
} microorganisms: alert for the improvement of necessity in teaching-learning process of biology

\begin{abstract}
This work aimed to analyze the knowledge of 327 students of 1st, 2nd and 3rd year of high school about microorganisms, as well as check the way these students interpret the microorganisms' activities related to their everyday life. Given the results is possible to consider that teachers need to use alternative teaching that lead to improved cognitive development, seeking to know the prior knowledge to mediate the relationship between what is known and new information.
\end{abstract}

KEYWORDS: Biology teaching. Misconceptions. Microbiology. 


\section{REFERÊNCIAS}

ALBUQUERQUE, G. G.; BRAGA, R. P. S.; GOMES, V. Conhecimento dos alunos sobre microrganismos e seu uso no cotidiano. Revista de Educação, Ciências e Matemática, Rio de Janeiro, v. 2, n. 1, p. 58-68, 2012. Disponível em: $<$ http://publicacoes.unigranrio.edu.br/index.php/recm/article/view/1913/941>. Acesso em: 02 abr. 2014.

ANTUNES, C. H.; PILEGGI, M.; PAZDA, A. K. Por que a visão científica da Microbiologia não tem o mesmo foco na percepção da Microbiologia no ensino médio? In: SIMPÓSIO NACIONAL DE ENSINO DE CIÊNCIA E TECNOLOGIA, 3., 2012, Ponta Grossa. Disponível em: $<$ http://www.sinect.com.br/2012/down.php?id=2799\&q=1 > Acesso em: 28 jul. 2014.

BARBOSA, F. H. F.; BARBOSA, L. P. J. L. Alternativas metodológicas em Microbiologia - viabilizando atividades práticas. Revista de Biologia e Ciências da Terra, Campina Grande, v. 10, n. 2, p. 143-143, 2010. Disponível em: <http://www.diaadiaeducacao.pr.gov.br/portals/pde/arquivos/281-4.pdf>. Acesso em: 14 mar. 2014.

BRANDÃO, L.; CORAZZA, M. J. Produção de wiki: uma ferramenta pedagógica para o desenvolvimento de pensamento conceitual dos estudantes do ensino médio. Scielo Brazil. 2008. Disponível em:

$<$ http://eduep.uepb.edu.br/rbct/sumarios/pdf/Artigo 15 V10 N2.pdf $>$. Acesso em: 16 jun. 2014.

CABRERA, W. B. A ludicidade para o ensino médio na disciplina de biologia: contribuições ao processo de aprendizagem em conformidade com os pressupostos teóricos da aprendizagem significativa. 2007. 158 f. Dissertação (Mestrado em Ensino de Ciências e Educação Matemática) - Universidade Estadual de Londrina - Londrina. Disponível em:

$<$ http://www.educadores.diaadia.pr.gov.br/arquivos/File/2010/artigos teses/Bio logia/Dissertacao/ludicidade.pdf>. Acesso em: 19 abr. 2014. de alunos de ensino médio a respeito das proteínas. Revista Ciências \& Educação, v.18, n.4, p.897-912, 2012. Disponível em: http://dx.doi.org/10.1590/S1516-73132012000400010. Acesso em: 04 de Nov. de 2015 
CASTRO, D. R.; BEJARANO, N. R. R. Conhecimentos prévios sobre seres vivos dos estudantes das séries iniciais da Cooperativa de Ensino de Central - COOPEC- BA. Revista Brasileira de Ensino de Ciências e Tecnologia, Ponta Grossa, v. 6, n. 1, p. 19-40, 2013. Disponível em:

<http://revistas.utfpr.edu.br/pg/index.php/rbect/article/view/951/967>. Acesso em: 18 jul. 2014.

FERNANDES, L. S.; CAMPOS, A. F.; MARCELINO JÚNIOR, C. A. C. Concepções alternativas dos estudantes sobre ligação química. Experiências em Ensino de Ciências, Mato Grosso, v.5, n. 3, p. 19-27, 2010. Disponível em: <http://if.ufmt.br/eenci/artigos/Artigo ID118/v5 n3 a2010.pdf>. Acesso em: 28 jul. 2014.

KIMURA, A. H. et al. Microbiologia para o ensino médio e técnico: contribuição da aplicação da ciência. Revista Conexão, Ponta Grossa, v. 9, n. 2, p. 254-267, 2013. Disponível em: <http://www.revistas2.uepg.br/index.php/conexao/article/view/5516/3664>. Acesso em: 10 maio. 2014.

LIMA, D. B.; GARCIA, R. N. Uma investigação sobre a importância das aulas práticas de Biologia no Ensino Médio. Cadernos do Aplicação, Porto Alegre, v. 24, n.1, 2011. Disponível em:

<http://seer.ufrgs.br/CadernosdoAplicacao/article/view/22262>. Acesso em: 14 mar. 2014.

LIMA, P.R.; SANTOS, L.M.; SILVA, E.L. Propostas para a reelaboração conceitual por meio de atividades experimentais. Revista de Educação, Ciências e Matemática. v.4, n.1, Jan/Abr, 2014. Disponível em: http://publicacoes.unigranrio.edu.br/index.php/recm/article/view/2110. Acesso em: 04 de Nov. de 2015.

LIMBERGER, K. M.; SILVA, R. M.; ROSITO, B. A. Investigando a contribuição de atividades experimentais nas concepções sobre Microbiologia de alunos do ensino fundamental. In: SALÃO DE INICIAÇÃO CIENTÍFICA PUCRS, 10., 2009. Anais... Disponível em:

<http://www.pucrs.br/edipucrs/XSalaolC/Ciencias Biologicas/Educacao em Biol ogia/71426-KAREN MARTINS LIMBERGER.pdf>. Acesso em: 28 jul. 2014.

MIRANDA, V. B. D. S.; LEDA, L. R.; PEIXOTO, G. F. A importância da atividade prática no ensino de biologia. Revista de Educação, Ciências e Matemática, Rio de Janeiro, v. 3, n. 2, p, 85-101, 2013. Disponível em: <http://publicacoes.unigranrio.edu.br/index. php/recm/article/view/2010>. Acesso: 01 jun. 2014. 
MORTIMER, E. F. Linguagem e formação de conceitos no ensino de ciências. Belo Horizonte: Editora UFMG, 2000.

OLIVEROS, P. B.; SILVEIRA, M. L.; ARAÚJO, M. F. Concepções espontâneas sobre vírus dos alunos do 6ㅇ ao 9ㅇ ano. In: ENCONTRO NACIONAL DE PESQUISA EM EDUCAÇÃO EM CIÊNCIAS, 8., 2011, São Paulo. Disponível em:

<http://www.nutes.ufrj.br/abrapec/viiienpec/resumos/R0346-1.pdf>. Acesso em: 20 jun. 2014.

PESSOA, T. M. S. et al. Percepção dos alunos do ensino fundamental da rede pública de Aracaju sobre a relação da Microbiologia no cotidiano. Scientia Plena, Sergipe, v. 8, n. 4, p.1-4, 2012. Disponível em:

<http://www.scientiaplena.org.br/sp/article/view/496/440>. Acesso em: 20 jul. 2014.

SILVA, M. S.; BASTOS, S. N. D. Ensino de microbiologia: percepções de docentes e discentes nas escolas públicas de mosqueiro, Belém, Pará. In.: ENCONTRO NACIONAL DE ENSINO DE CIÊNCIAS DA SAÚDE E DO AMBIENTE, 3., 2012, Niterói. Disponível em:

$<$ http://www.ensinosaudeambiente.com.br/eneciencias/anaisiiieneciencias/trab alhos/T114.pdf>. Acesso em: 25 jul. 2014.

SILVEIRA, M. L.; OLIVEROS, P. B.; ARAÚJO, M. F. F. Concepções espontâneas sobre bactérias de alunos do 6으 ao 9o ano. In: ENCONTRO NACIONAL DE PESQUISA EM EDUCAÇÃO EM CIÊNCIAS, 8., 2011, São Paulo. Resumos... Disponível em: <http://www.nutes.ufrj.br/abrapec/viiienpec/resumos/R0347-1.pdf>. Acesso em: 11 jan. 2014.

VIVEIRA, A. A.; DINIZ, R. E. S. As atividades de campo no ensino de ciências: reflexões a partir das perspectivas de um grupo de professores. Revista Scielo, Editora UNESP: São Paulo, 2009. Disponível em:

<http://books.scielo.org/id/g5q2h/03>. Acesso em: 07 mar. 2014. 
Recebido: 20 jan. 2015

Aprovado: 06 jun. 2016

DOI: $10.3895 /$ rbect.v9n1.2031

Como citar:

OLIVEIRA, N. F.; AZEVEDO, T. M.; NETO, L. S. Concepções alternativas sobre microrganismos: alerta para a necessidade de melhoria no processo ensino-aprendizagem de biologia. Revista Brasileira de Ensino de Ciência e Tecnologia, v. 9, n. 1, p. 260-276, jan./abr. 2016. Disponível em:

$<$ https://periodicos.utfpr.edu.br/rbect/article/view/2031>. Acesso em: xxx.

\section{Correspondência:}

Noalixon Faustino de Oliveira

Centro de Educação e Saúde, Olho D'água da Bica S/N, 58175-000, Cuité, Paraíba, Brasil.

Thamara de Medeiros Azevedo

Centro de Educação e Saúde, Olho D'água da Bica S/N, 58175-000, Cuité, Paraíba, Brasil

Luiz Sodré Neto

Centro de Educação e Saúde, Olho D’água da Bica S/N, 58175-000, Cuité, Paraíba, Brasil

Direito autoral: Este artigo está licenciado sob os termos da Licença Creative Commons-Atribuição 4.0 Internacional. 